\title{
- papel da Santa Casa no sistema público de saúde brasileiro: o levantamento histórico de uma instituição filantrópica
}

\section{The Role of Santa Casa in the Brazilian Public Health System: the historical research of a philanthropic institution}

\author{
André Luiz Mendes Oliveira ${ }^{a}$ \\ (D) https://orcid.org/0000-0002-9284-7529 \\ E-mail: andre.mendesळifsp.edu.br

Mário Sacomano Neto
(D) https://orcid.org/0000-0002-2561-1700
E-mail: msacomano@ufscar.br
Júlio César Donadoneb
(D) https://orcid.org/0000-0002-2129-0129
E-mail: julio@dep.ufscar.br
anstituto Federal de Educação, Ciência e Tecnologia de
São Paulo-Campus São Carlos. São Carlos, SP, Brasil.
bUniversidade Federal de São Carlos. Centro de Ciências
Exatas e Tecnologia. Departamento de Engenharia de
Produção. São Carlos, SP, Brasil.

\section{Resumo}

O artigo $^{1}$ tem por objetivo analisar a evolução da interação entre Santas Casas e o Sistema de Saúde Público brasileiro por meio do levantamento histórico da Santa Casa de Mogi Mirim. Os procedimentos metodológicos foram de abordagem qualitativa e basearam-se em uma coleta de dados por pesquisa documental do levantamento histórico da Santa Casa em questão e do histórico dos principais marcos do sistema de saúde brasileiro. Os dados obtidos foram analisados para identificar o nível de interação entre a Santa Casa e a assistência hospitalar do sistema de saúde em vigor. O resultado desta análise histórico-comparativa demonstrou a intensificação da relação entre a Santa Casa e o sistema público de saúde, partindo de uma interação nula no início do século XIX que se transforma em uma codependência cercada de disputas e com limites muitos tênues no início do século XXI.

Palavras-chave: Santas Casas; Sistema de Saúde; SUS.

\section{Correspondência}

André Luiz Mendes Oliveira

Estrada Municipal Paulo Eduardo de Almeida Prado, s/n, São Carlos, SP, Brasil. CEP 13565-820.

\footnotetext{
Este artigo foi elaborado a partir da coleta de dados realizada para a tese de doutorado "A Transformação de um Campo e suas Concepções de Controle: o caso de uma Santa Casa”, elaborada por André Luiz Mendes Oliveira e defendida junto ao Programa de Pós-Graduação em Engenharia de Produção da Universidade Federal de São Carlos.
} 


\section{Introdução}

This article aims to analyze the evolution of the interaction between Santas Casas and the Brazilian Public Health System from the historical research of the Santa Casa de Mogi Mirim. This qualitative research was based on data collected by means of a documentary research on the historical survey of Santa Casa and the Brazilian health system, identifying the level of interaction between the institution and hospital assistance. The result of this comparative historical analysis demonstrated the intensification of the relationship between Santa Casa and the public health system, starting from a null interaction in the beginning of the 19th century that turns into a co-dependency with numerous disputes and very tenuous limits in the beginning of the 21st century.

Keywords: Santas Casas; Health System; SUS
A Constituição Federal Brasileira de 1988 trouxe consigo uma inovação para o sistema de saúde público brasileiro: a criação do Sistema Único de Saúde (SUS). 0 sistema foi considerado inovador por atuar com dois eixos norteadores: a integralidade e a universalidade, características que não existiam no funcionamento dos sistemas de saúde anteriores.

Ao criar o SUS, o poder público não possuía estrutura para garantir o pleno atendimento da população e garantiu, ainda no texto da Constituição de 1988, a possibilidade de contratação de serviços de saúde da esfera privada para complementar a rede de atendimento, priorizando a contratação de serviços de entidades filantrópicas e sem fins lucrativos. Esta categoria que incluiu as Santas Casas, instituições muitas vezes centenárias cujas atividades de origem eram filantrópicas e de caridade, e que passaram a desempenhar o papel de prestadores de serviços remunerados pelo Estado.

Pouco mais de 30 anos após a criação do SUS, o campo de pesquisa em saúde vem debatendo as razões que têm mitigado o funcionamento pleno do sistema de saúde, tais como a descentralização da gestão ao nível dos municípios (Miranda; Mendes; Silva, 2017; Santos, 2012) e o "empresariamento" da assistência à saúde (Viana; Miranda; Silva, 2015). Já o segmento da saúde beneficente indica um quadro caótico (CMB, 1992): uma dívida do setor que chegou aos $R \$ 15$ bilhões (15 bilhões de reais) e o maior hospital de urgência e emergência da América Latina, a Santa Casa de São Paulo paralisou seu atendimento em 22 de julho de 2014 por 28 horas por falta de materiais e medicamentos.

Uma pesquisa realizada pelos autores utilizando o termo "Santa Casa" nas bases de dados Web of Science e SciELO, considerando os trabalhos publicados entre 2011 e 2020 - excluindo os trabalhos que descrevem técnicas cirúrgicas - totalizou 43 trabalhos acadêmicos na base de dados Web of Science e 26 trabalhos na base de dados SciELO. Os trabalhos que adotavam abordagens históricas de uma Santa Casa específica se restringiam apenas a um determinado período de sua história e assim foi identificada uma oportunidade para discutir a relação das Santas Casas com o sistema de saúde brasileiro. Considerando que a relação entre as políticas de 
saúde brasileiras, sua assistência hospitalar e as Santas Casas teve diferentes níveis de interação no decorrer da história, o objetivo deste artigo é apresentar a evolução - ou absorção - do papel das Santas Casas dentro da rede de assistência hospitalar ao longo do desenvolvimento do Sistema Público de Saúde brasileiro a partir do levantamento histórico da Santa Casa de Misericórdia de Mogi Mirim/SP.

Este artigo foi elaborado com dados obtidos para uma tese de doutorado que analisou uma Santa Casa como um Campo de Ação Estratégica. Os procedimentos metodológicos aplicados durante a elaboração do artigo foram desenvolvidos com abordagem qualitativa envolvendo pesquisa documental por meio: (1) da busca por produções científicas sobre o sistema de saúde brasileiro ao longo da história nas bases de dados Web of Science e SciELO; e (2) da pesquisa nos Arquivos do Centro Histórico de Documentação de Mogi Mirim. Ao término da coleta de dados, foram selecionados os principais eventos relacionados à assistência à saúde como delimitadores dos períodos de estudo do sistema de saúde, acrescentando o relato histórico da Santa Casa de Mogi Mirim e sua interação com o referido sistema de saúde.

\section{Gênese da Santa Casa de Mogi Mirim}

As mais antigas Santas Casas foram instaladas logo após o descobrimento e nas primeiras vilas criadas no litoral brasileiro, como por exemplo Salvador, Santos e Rio de Janeiro. Em função disso, o foco inicial de atendimento dessas Santas Casas era evitar as doenças trazidas por marinheiros que chegavam aos portos brasileiros - principal preocupação de "saúde pública" da época.

Segundo Baptista (2007), a chegada da família real em terras brasileiras no início do século XIX contribuiu diretamente para o surgimento das primeiras ações de saúde pública. Essas práticas buscaram garantir que a mão-de-obra disponível estivesse saudável, de forma a permitir a continuidade dos negócios implementados pela realeza em sua colônia.

Essa lógica de saneamento das cidades e combate às doenças - que perdurou até a Primeira República fez com que os médicos ganhassem espaço na prestação de serviços àqueles que podiam arcar com o valor de seus honorários, enquanto as Santas Casas recebiam os indigentes e os pobres ${ }^{2}$ que, por sua vez, eram atendidos por um pequeno grupo de médicos voluntários.

A Irmandade da Santa Casa de Misericórdia de Mogi Mirim foi fundada em 6 de abril de 1867 por iniciativa do padre Luiz José de Brito, Dr. Delfino Pinheiro de Ulhôa Cintra, José Costa Rangel, Albano Leite da Cunha Canto e José Alves dos Santos, sendo regida pelo compromisso aprovado em 30 de agosto de 1867 por Dom Sebastião Pinto do Rego, bispo diocesano de São Paulo, e por Dr. José Tavares Bastos, presidente da província de São Paulo.

Em 1882, 15 anos depois da fundação da Irmandade, os recursos arrecadados ainda eram insuficientes para iniciar as obras do hospital. Nesse ano, o Governo da Província destinou o produto da $48^{\text {a }}$ loteria da Província, a importância de 12:0oo\$ooo (doze contos de réis), para a instituição e nomeou uma comissão para administrar a construção do hospital, tendo o tenente-coronel José Batista da Luz como presidente. A primeira reunião ocorreu em maio de 1882 e a comissão decidiu aceitar a doação de um terreno oferecido pelo próprio presidente da comissão para a construção do prédio.

A pedra fundamental foi lançada em 6 de julho de 1883 e a sociedade mogimiriana buscou angariar recursos para custear a construção do hospital com quermesses, espetáculos, leilões e festas de caridade.

A inauguração do hospital ocorreu em 3 de junho de 1888, 21 anos após a fundação da Irmandade e quase cinco anos após o lançamento da pedra fundamental, atendendo aos pobres

\footnotetext{
2 Os dados históricos obtidos definem o perfil dos atendidos na Santa Casa de Mogi Mirim, no final do século XIX e início do século XX, como pessoas negras, acima de 60 anos, viúvas e sem ocupação. Entretanto, esse perfil não pode e nem deve ser generalizado para todas as Santas Casas. Em A Santa Casa de Misericórdia da Bahia e a Assistências aos Doentes no Século XIX, Barreto (2011) destaca que, ao longo do século XIX, mesmo atendendo a pobres e indigentes, a maior parte dos enfermos atendidos no Hospital São Cristóvão, em Salvador, administrado pela Santa Casa de Misericórdia da Bahia, era composta de brancos, estrangeiros e com ocupação definida. As características distintas entre os atendidos em Mogi Mirim e em Salvador demonstram que a análise do perfil dos assistidos pelas Santas Casas é uma discussão obrigatória nos estudos dessas instituições, uma vez que os resultados podem variar em função do recorte geográfico e/ou temporal aplicados à pesquisa.
} 
e indigentes até 1895 quando fechou as portas para realizar uma reorganização interna. Em 7 de fevereiro de 1897 houve a reabertura da Santa Casa de Misericórdia de Mogi Mirim, sob a provedoria do capitão Miguel Antunes Pereira Lima e contando com o trabalho voluntário de quatro médicos que residiam na cidade: Dr. Carlos Augusto Fernandes de Castro, Dr. Tertuliano César Gomide, Dr. Matheus Chaves de Mattos e Dr. Pedro de Souto Mayor.

A partir de 5 de julho de 1899 a provedoria ficou a cargo do coronel João Leite do Canto - capitalista, grande produtor de café e grande benfeitor do município - que ocupou o cargo por 17 anos e meio. Em 190o, durante o mês de julho, haviam sido atendidos 14 enfermos no hospital: um movimento considerado modesto para os padrões atuais.

O fim da escravidão gerou um aumento do número de colonos nas propriedades rurais, principal engrenagem da economia do município na época, e consequentemente um aumento do movimento hospitalar. Em novembro de 1916, os médicos da cidade deram início ao "Movimento de Interesse pela Santa Casa”, uma lista contendo as reformas necessárias para melhorar o atendimento realizado pela Santa Casa, não apenas aos pobres e indigentes, mas também aos "pensionistas", ${ }^{3}$ categoria incluída nos relatórios da Irmandade para indicar os pacientes que tinham condições de pagar pelos atendimentos que recebiam no hospital.

Esse movimento médico encerra a fase dos produtores de café na provedoria da instituição. Em 1917, o cargo é assumido por um dos médicos da Santa Casa: Dr. Altino Joaquim de Almeida. A necessidade de adaptação da estrutura física em razão do aumento do número de atendimentos resultou em um maior número de irmãos para viabilizar as reformas necessárias. Em novembro de 1919, após uma generosa doação do coronel João Leite, ex-provedor da Santa Casa, foi inaugurado o pavilhão Coronel João Leite para assistência aos tuberculosos.

\section{As Caixas de Previdência e os Institutos de Aposentadoria e Pensão}

Em 24 de janeiro de 1923, com base em uma proposta elaborada pelo chefe de polícia Eloy Chaves, o Decreto n. 4.628 - posteriormente conhecido como Lei Eloy Chaves - entrou em vigor para regulamentar uma prática assistencial existente em algumas empresas: as Caixas de Aposentadoria e Previdência (CAP) (Baptista, 2007).

Essas caixas eram um benefício oferecido por empresas de grande porte, em que o trabalhador contribuía com parte de seu salário e a empresa com parte de sua renda, garantindo ao trabalhador participante e a toda sua família socorro médico e medicamentos, aposentadorias e pensões para os herdeiros. As CAP eram administradas pelas próprias empresas e por seus trabalhadores e atuavam como um seguro: o trabalhador podia procurar um médico credenciado para o atendimento e os valores gastos pelo trabalhador/segurado eram reembolsados posteriormente. 0 papel do Estado era mediar possíveis conflitos entre os trabalhadores e a empresa, não sendo responsável por financiar ou supervisionar as CAP.

As reformas realizadas no prédio da Santa Casa de Mogi Mirim entre 1918 e 1919, bem como a construção de uma sala cirúrgica em meados da década de 1920 possibilitaram melhorar o atendimento hospitalar realizado, porém o prédio ainda teve que passar por diversas intervenções emergenciais relacionadas a problemas em praticamente todos os elementos estruturais: paredes, pisos e tetos. Nesse período, o foco principal de atendimento continuou sendo os pobres e os indigentes, mas havia também um pequeno número de atendimentos particulares.

Em 1933, o Estado criou os Institutos de Aposentadoria e Pensões (IAP) e passou a desempenhar os papéis de controlador, financiador e administrador do sistema. Enquanto as CAP representavam uma única empresa,os IAP representavam categorias de trabalhadores, independente da empresa em

30 termo "pensionista" nesse momento histórico origina-se do hóspede pagante das pensões, aquela pessoa detentora de recursos financeiros para usufruir dos serviços oferecidos no local, como hospedagem, alimentação, banho etc. Não se tratava ainda de um beneficiário das Caixas de Aposentadoria e Previdência e nem dos Institutos de Aposentadoria e Pensões, mas das pessoas que podiam pagar pelo atendimento no hospital, realizado de forma e em instalações diferenciadas daquelas destinadas aos pobres e indigentes. 
que trabalhavam. Os Institutos de Aposentadoria e Pensões criados foram:

(1) IAPTEC, aos trabalhadores em transporte e cargas;

(2) IAPC, aos trabalhadores comerciários;

(3) IAPI, aos trabalhadores industriários;

(4) IAPB, aos trabalhadores bancários;

(5) IAPM, aos trabalhadores marítimos e portuários;

(6) IPASE, aos trabalhadores públicos.

Os IAP ampliaram o número de atendidos, mas não de maneira universal, já que para gozar dos benefícios do Instituto o cidadão deveria ter um vínculo empregatício em uma das categorias definidas pelo governo, fato que causou a segregação de outras categorias de trabalhadores, como os trabalhadores rurais, profissionais liberais, entre outros. Mas a discriminação ocorreu também entre os próprios Institutos, já que a gestão independente de cada IAP não permitiu a uniformização dos benefícios oferecidos, ou seja, institutos de categorias com maior poder econômico, como os bancários e os industriários por exemplo, ofereceram assistência maior e melhor que a assistência dos demais institutos. Justamente por essa diferença de capacidade de arrecadação, nem todos os IAP ofereceram assistência médica a seus membros, assim como a construção de hospitais próprios foi viável apenas em algumas localidades, como o hospital do IAPM no Rio de Janeiro atual Hospital Geral do Andaraí.

A partir de 1935, com a eleição do Dr. Lúcio Cintra do Prado, juiz da comarca, para o cargo de provedor da Santa Casa de Mogi Mirim, teve início uma nova onda de reformas, bem como a adaptação de uma maternidade de 10 leitos no pavilhão coronel João Leite no final de 1940.

Em maio de 1943, as condições estruturais críticas do prédio do hospital levaram à idealização de um novo prédio hospitalar para a Irmandade em um terreno próximo ao antigo cuja pedra fundamental foi lançada em 2 de agosto de 1945. A sociedade mogimiriana teve, novamente, grande parcela de contribuição para a construção do novo hospital: além das doações realizadas por diversas figuras de destaque da sociedade, foram organizados diversos eventos beneficentes. Em virtude do risco de desabamento do antigo prédio, a solenidade de inauguração do novo prédio, mesmo inacabado, foi realizada em agosto de 1953 e a conclusão das obras do novo prédio ocorreu no final da década de 1950 após a Irmandade receber um aporte financeiro por meio de subvenções governamentais.

\section{O Instituto Nacional de Previdência Social e o Instituto Nacional de Assistência Médica da Previdência Social}

Durante a década de 1960, no governo Jânio Quadros, a discussão de uma proposta para uniformizar os benefícios prestados pelos IAP culminou, em setembro de 1966, com a unificação dos institutos em um único: o Instituto Nacional de Previdência Social (INPS). Além da uniformização dos benefícios conforme esperado por seus idealizadores, a unificação trouxe também uma série de reclamações dos contribuintes que gozavam de mais benefícios, afinal a assistência dos institutos de maior poder econômico também passou a ser usufruída pelos demais contribuintes que contribuíam com valores menores e cuja rede assistencial não apresentava a mesma qualidade. Esta migração de contribuintes em busca de atendimento em outros institutos causou a superlotação de alguns hospitais, gerou filas, demora no atendimento e outros problemas que resultaram em insatisfação geral dos contribuintes.

Na tentativa de atender à nova demanda gerada, o Estado começou a contratar serviços por meio de credenciamento de hospitais privados para complementar a rede de atendimento disponível, formando a estrutura que ficou conhecida como complexo médico-empresarial (Cordeiro, 1984).

Também na década de 1960, após a conclusão das obras de construção do novo prédio, a Santa Casa de Mogi Mirim firmou o convênio para atender aos conveniados do Instituto Nacional de Previdência Social (INPS). A entrada dos usuários do INPS aumentou o movimento hospitalar e a mesa diretora, contando com o sr. José Martinelli como provedor, que decidiu contratar, em junho de 1968, uma equipe de arquitetos especializados para traçar um plano diretor - aprovado em setembro daquele ano - que contemplasse a ampliação do hospital considerando a área não utilizada do terreno. 0 plano diretor começou a ser implementado em 1969, com o 
Dr. Gastão de Oliveira Delafina ocupando o cargo de provedor da Irmandade, a partir da adoção de práticas administrativas e operacionais apontadas pelo referido plano. A implementação dessas práticas resultou em algumas mudanças, tais como: substituir a função voluntária de Mordomo ${ }^{4}$ pela função remunerada de Administrador, a adoção de contabilidade hospitalar, a criação de um setor de pessoal para supervisionar as ações de recrutamento e seleção de funcionários, além de contratar uma enfermeira diplomada para a função de chefia. ${ }^{5}$

Já as obras de ampliação que constavam do plano diretor tiveram início em janeiro de 1974 com a construção de uma nova lavanderia e, no local da antiga, a instalação de um Centro Radiológico. No ano seguinte a Unidade de Terapia Intensiva foi construída e em 1976 as dependências que eram utilizadas como clausuras pelas irmãs de caridade se transformaram em apartamentos para pacientes particulares. A construção de novas instalações para cozinha refeitório foi realizada a partir de 1978, graças ao recebimento de nova subvenção governamental, com finalidade específica, que também permitiu a ampliação do Pronto Socorro e a construção de áreas para Maternidade e Pediatria.

No final da década de 1970, uma das primeiras ações adotadas pelo Estado para amenizar os efeitos da crise do sistema previdenciário foi aumentar o controle sobre os recursos aplicados na assistência médico-hospitalar e para isso foi criado, em 1977, o Instituto Nacional de Assistência Médica da Previdência Social (INAMPS), órgão responsável por coordenar todas as ações de saúde de nível médicoassistencial da previdência social.

Já no início dos anos 1980, os primeiros sinais de recessão econômica e a crise financeira da previdência anunciaram um processo que se aprofundou no final daquela década com o

[...] desaparecimento progressivo do Instituto Nacional de Assistência Médica da Previdência Social (INAMPS) enquanto financiador e prestador da assistência médica dos trabalhadores, devido à redução da qualidade dos serviços pelo esmagamento dos preços pagos ao setor privado contratado e à extinção dos convênios INAMPS/ empresa e INAMPS/sindicato. (Medici, 1992, p. 9)

A deterioração dos valores de serviços custeados pelo INAMPS em função da inflação do período permitiu uma ruptura unilateral de vários convênios e contratos por parte dos hospitais. De modo resumido, em meados da década de 1980, a deterioração dos serviços previdenciários gerou, um crescimento da demanda por serviços médicos diferenciados, em especial pelos operários qualificados, assalariados, executivos e profissionais liberais, enquanto do lado da oferta houve um favorecimento do Estado por meio da presença sistemática de incentivos governamentais ao sistema privado de saúde destinado à cobertura das pessoas inseridas no mercado formal de trabalho.

\section{Sistema Único de Saúde (SUS)}

A crise do setor previdenciário, mesmo com a criação do INAMPS, se estendeu ao setor de saúde afetando as Santas Casas que deixaram de receber o repasse de recursos financeiros, seja por contingenciamento do Instituto, seja por revisão dos relatórios de atendimento apresentados.

Em 1981, o Conselho Consultivo de Administração da Saúde Previdenciária (CONASP) criou um grupo de trabalho específico para buscar identificar as causas da crise no setor e o diagnóstico apontou para um conjunto de distorções existentes que reforçaram os argumentos do movimento sanitário por uma reforma do sistema de saúde brasileiro:

(1) serviços inadequados à realidade;

(2) insuficiente integração dos diversos prestadores;

(3) recursos financeiros insuficientes e cálculo imprevisto;

(4) desprestígio dos serviços próprios;

(5) superprodução dos serviços contratados.

40 Mordomo, na Santa Casa de Mogi Mirim, era responsável por inspecionar as instalações do hospital e autorizar o pagamento das contas referentes ao custeio do hospital. A criação de um cargo remunerado garantiria a dedicação integral e profissional ao hospital. 5 A função de enfermagem era desempenhada desde 1935 por um grupo de religiosas da congregação das Irmãs Franciscanas do Coração de Maria, auxiliadas por pessoas que muitas vezes não tinham sequer uma formação acadêmica na área da saúde. 
O Ministério da Saúde convocou, em 1986, a VIII Conferência Nacional de Saúde (VIII CNS) que pela primeira vez contou com a participação da comunidade e dos técnicos nas discussões. O relatório da VIII CNS, além de ter sido utilizado como instrumento de pressão política, foi aceito também como material de referência pela Assembleia Constituinte 1987/1988. A Constituição de 1988 legalizou o relatório da VIII CNS ao criar o SUS baseado em quatro princípios:

(1) universalização às ações e serviços de saúde;

(2) integralidade da atenção;

(3) descentralização com direção única do sistema; (4) participação popular.

A universalização do atendimento causou um efeito de superlotação da capacidade instalada no serviço público e por isso o SUS permitiu que hospitais privados fossem conveniados à rede de atendimento na tentativa de suprir a demanda gerada.

Com o SUS surge a categoria "usuário SUS" nos relatórios de atendimentos da Santa Casa de Mogi Mirim unificando as categorias de atendimento "ao contribuinte" e "ao indigente" ou "gratuito". A descentralização de recursos permitiu também às Santas Casas firmarem convênios diretamente com as esferas municipal e estadual para a prestação de serviços ao SUS.

Em janeiro de 1991, o provedor da Santa Casa, Lúcio Ratz, informou à Prefeitura Municipal de Mogi Mirim que o hospital se encontrava em uma crise financeira que fora agravada pelos reajustes salariais concedidos aos funcionários do hospital e que a mesa administrativa estava disposta a entregar o hospital ao município. Após a criação de uma comissão de vereadores para analisar o assunto, foram apresentadas algumas alternativas ao poder público e optaram pela liberação de uma subvenção governamental de custeio ao hospital, ação que já havia sido realizada em julho de 1990. Porém, em janeiro de 1992, novas negociações salariais convergiram em três horas de paralisação de 70\% do quadro operacional do hospital e o acordo obtido para retomada das atividades indicava uma nova crise financeira nos meses seguintes.

A Mesa Administrativa da Santa Casa e o Poder Executivo voltaram a se reunir em busca de uma solução para a situação do hospital e, em 1992, nascia o “acordo de Cooperação Técnica e Gerencial de Saúde na Santa Casa”, um convênio entre a Prefeitura Municipal, a Secretaria de Estado da Saúde (SES) e a Santa Casa de Mogi Mirim, que ficou conhecido entre as partes como Co-Gestão.

ACo-Gestão permitiu ao hospital ter acesso a outros níveis de recursos financeiros por meio de subvenções governamentais, porém a mesa administrativa passou a ter $50 \%$ de sua composição eleita pelo Conselho Municipal de Saúde e nomeada pelo Prefeito Municipal. Além da composição mista, o acordo implementou um sistema de revezamento entre os cargos na Mesa CoGestora e no Conselho Fiscal, de forma a garantir uma equidade entre membros da Irmandade e membros nomeados pelo Poder Público durante os mandatos.

Com o passar do tempo, as subvenções governamentais concedidas por meio da Co-Gestão converteram-se em contratos de prestação de serviços complementares ao SUS, acarretando um novo modelo de gerenciamento do hospital que permitiu acompanhar o cumprimento das metas contratadas. Esse novo modelo trouxe consigo diversas parcerias privadas que realizaram obras de reestruturação física no hospital.

A formatação de composição da Mesa Co-Gestora por meio de revezamento entre membros da Irmandade e do Poder Público vigorou até 2003, pois um novo estatuto aprovado em janeiro de 2004 definiu que o hospital seria conduzido por uma mesa diretora composta por membros da Irmandade e que, caso houvesse convênios celebrados com o poder público, poderiam ser convidados representantes da outra parte para compor a mesa. Esse novo estatuto não estremeceu as relações entre a Santa Casa e o Poder Público, já que em 2005 a Prefeitura Municipal inaugurou um anexo ao prédio da Santa Casa, construído com recursos públicos, para abrigar a Unidade de Atendimento Não Agendado (UANA), responsável por atender casos de média complexidade que até então eram realizados no Centro de Especialidades Médicas (CEM) do município. 0 gerenciamento e a operação da UANA ficaram sob responsabilidade da Santa Casa até o final de 2017 , quando não houve acordo entre as partes para a renovação do contrato.

Nesse período, outros convênios complementares com o SUS foram firmados, a fim de garantir um número mínimo de cirurgias eletivas dentro do município, plantões a distância de algumas 
especialidades para o pronto atendimento, ambulatório de ortopedia, entre outros.

Em 2010, a Irmandade adotou um plano de expansão que incluía:

(1) a diversificação do número de convênios atendidos por meio do credenciamento de novos convênios e acabando com a exclusividade do atendimento do convênio Unimed;

(2) a obtenção de um empréstimo para a construção de 40 novos leitos de internação aos novos usuários de convênios particulares e para a compra de um imóvel adjacente ao hospital onde se instalou o Centro Administrativo da Santa Casa;

(3) a implantação de ambulatórios - chamados de centros médicos - em área externa ao hospital, sendo um em Itapira/SP em 2011 e outro em Mogi Mirim em 2012 para atendimento dos usuários dos novos convênios credenciados.

Com a proximidade do fim dos contratos complementares de atendimento ao SUS em 2011, a negociação pela renovação do contrato com a Prefeitura ganhou notas bélicas em virtude dos valores pretendidos pelo hospital e, após a mediação do Ministério Público, os convênios foram renovados totalizando um aumento de 31,25\% nos valores a serem recebidos pela Santa Casa. Ressalta-se que esses valores não eram destinados a investimentos, mas se restringiam ao custeio dos serviços prestados ao SUS.

Entretanto, a estratégia de expansão e o endurecimento da postura durante as negociações de renovação dos contratos de convênios públicos e privados resultou na interrupção do atendimento dos usuários da Unimed na Santa Casa em meados de 2012, causando a queda de cerca de $30 \%$ da receita do hospital. Em seguida o corpo clínico anunciou que o atendimento médico aos usuários do SUS seria interrompido, pois o repasse dos valores referentes aos contratos com o SUS vinha sofrendo atrasos recorrentes.

Considerando que a Santa Casa era o único hospital da cidade credenciado para atender aos usuários do SUS, a Prefeitura Municipal solicitou a intervenção judicial junto ao Ministério Público, alegando que (1) a Santa Casa havia recebido integralmente os valores dos contratos com o SUS, (2) não havia repassado os valores ao Corpo Clínico e (3) por diversas vezes ao longo do ano não entregara a prestação de contas dos valores recebidos. Apesar do
Ministério Público não acatar o pedido de intervenção judicial, a Prefeitura Municipal realizou a interdição em agosto de 2012 por meio de um decreto municipal que destituiu a Mesa Diretora e tornou sem efeito o Estatuto e o Regimento Interno do hospital. A intervenção se estendeu até novembro de 2012.

Em 2019, com denúncias de desvio de dinheiro público, falta de pagamento de honorários médicos, suspensão de atendimento no ambulatório de ortopedia e na Unidade de Terapia Intensiva Neonatal, o Ministério Público determinou uma nova intervenção no hospital, mas dessa vez parcial: a Prefeitura Municipal tornou-se responsável apenas pela operação do atendimento dos usuários do convênio SUS. Logo após a intervenção, o prefeito municipal comunicou à sociedade mogimiriana que a Santa Casa não tinha mais condições de atender ao SUS e anunciou a construção de um Hospital Municipal que atenderia à demanda de todos os usuários SUS do município.

Entretanto esse anúncio causou grande turbulência política, uma vez que a construção de um Hospital Municipal dependeria da aprovação de um projeto de lei que alterasse os anexos do Plano Plurianual do município. Mesmo a base aliada do poder executivo na Câmara Municipal sendo formada pela maioria dos vereadores, as dúvidas em relação ao tema fizeram com que a votação do projeto de lei fosse postergada duas vezes. Durante esse período de postergação, o mês de maio de 2019 foi marcado por dois eventos: uma reunião técnica com a Diretoria Regional de Saúde (DRS) de São João da Boa Vista organizada por um dos vereadores, e uma audiência pública convocada pelo vice-presidente da Câmara na tentativa de esclarecer e detalhar melhor o projeto do hospital municipal.

O principal objetivo da reunião técnica com a DRS era firmar um acordo para que o projeto fosse enquadrado como hospital regional e assim obter financiamento da esfera estadual para seu financiamento. Porém, o diretor regional argumentou que além de não existir uma evasão significativa de pacientes daquela DRS para outras - indicando uma demanda superior à oferta de serviços médicos ofertados - não havia nenhum programa previsto para o credenciamento de novos hospitais regionais.

A audiência pública proposta para explicar e detalhar o projeto do hospital também não teve os efeitos esperados: os servidores do primeiro 
escalão do poder executivo apresentaram discursos contraditórios, demonstrando a inexistência de um projeto executivo ou um plano de ação ou até mesmo um orçamento prévio para a construção e operacionalização do hospital municipal. Outra linha de argumentação adotada por esses servidores abordou o fato da Santa Casa ser um hospital privado e que havia o risco dos convênios de atendimento ao SUS não serem renovados com a Irmandade.

Dos 17 vereadores, 16 estiveram presentes na audiência pública e um número considerável indicou, em seus pronunciamentos, a preocupação com a elevação dos gastos públicos - alguns apresentaram números do município vizinho, demonstrando que o custo para manter um hospital municipal seria muito maior do que os valores dos convênios com a Santa Casa. Outros pontos destacados pelos vereadores foram os prováveis desdobramentos do encerramento do convênio com a Santa Casa: o possível fechamento de uma instituição centenária no município e o fechamento de mais de 200 postos de trabalho ligados ao funcionamento do hospital.

O último momento da audiência pública contou com a tribuna livre em que alguns representantes da sociedade mogimiriana fizeram uso da palavra. As posições apresentadas nesse momento podem ser sintetizadas em três eixos: (1) os recursos que seriam utilizados na construção de um hospital municipal poderiam ser investidos para melhorar a infraestrutura das Unidades Básicas de Saúde do município; (2) o custo de um hospital privado filantrópico é menor que um hospital público; e (3) a péssima experiência da instalação de um hospital municipal no município vizinho que resultou em uma estrutura obsoleta e ociosa.

A ausência de um projeto viável, a falta de articulação política com a esfera estadual e com a Câmara e a pressão popular - seja para investimentos na Atenção Básica, seja em defesa da Santa Casa não poderiam trazer outro resultado: no início de junho de 2019, a Câmara Municipal votou o projeto de lei para alteração dos anexos do Plano Plurianual e o projeto foi rejeitado por 14 votos a 2.

\section{Considerações finais}

Analisar as interações da assistência hospitalar do sistema de saúde brasileiro com as Santas Casas a partir da análise histórica da Santa Casa de Mogi Mirim permitiu visualizar como essa relação se intensifica com o passar dos anos.

Durante o século XIX e metade do século XX não havia um sistema de saúde público com retaguarda hospitalar para toda a população brasileira. Enquanto os mais abastados eram atendidos por médicos particulares, os pobres e indigentes dependiam da caridade e filantropia das Santa Casas.

Entretanto, com a economia agrícola dando lugar para a economia industrial, o surgimento das Caixas de Aposentadoria e Pensão e, posteriormente, dos Institutos de Aposentadoria e Pensões, o sistema de saúde brasileiro começou a atender uma parcela da população economicamente ativa e intensificou o atendimento de uma nova categoria nas Santas Casas: os pacientes particulares. Além do atendimento gratuito aos indigentes, as Santas Casas passaram a ter uma parcela de faturamento por meio desses atendimentos particulares, o que as levou a melhorar suas instalações a fim de atrair esse público para o atendimento no próprio município, evitando que os pacientes tivessem que realizar grandes viagens em busca de tratamentos médicos mais complexos.

A criação do INPS e o credenciamento das Santas Casas para atender aos conveniados do INPS inseriu os hospitais filantrópicos definitivamente na retaguarda hospitalar do sistema público de saúde e atendendo a todas as categorias: os conveniados do INPS, os demais trabalhadores, os pacientes particulares, os pobres e os indigentes. Esse período trouxe também um grande volume de recursos financeiros injetados pelo poder público nas Santas Casas a fim de melhorar a estrutura de atendimento aos conveniados do INPS.

A crise do sistema INPS/INAMPS e a criação do SUS trouxeram a independência financeira na gestão de recursos para a saúde por parte dos municípios, mas também os tornaram diretamente responsáveis por garantir o atendimento integral e universal de sua população. Isto acarretou novos modelos de contratação de serviços e de gerenciamento da saúde. Não se trata mais apenas de remunerar por serviços contratados, mas de garantir que tais serviços estejam à disposição da população. Os episódios envolvendo as intervenções de 2012 e 2019 e a possibilidade de construção de um hospital municipal são exemplos claros 
da competição política entre público e privado indicada por Bahia (2018), em que não apenas existe uma disputa por recursos materiais, mas por um capital simbólico extremamente valorizado pelo prefeito municipal: “ “quem é que manda na saúde?”. O caso estudado indica não apenas a tendência a uma postura mais reguladora em detrimento a uma diretamente executora (Goya et al, 2016), mas a necessidade de firmar posições políticas junto à própria Irmandade para garantir a retaguarda hospitalar necessária ao município.

O objetivo deste artigo foi analisar como se desenvolveu a interação entre as Santas Casas e o sistema de saúde brasileiro a partir da retaguarda hospitalar. Após verificar duas intervenções municipais no hospital da Santa Casa de Mogi Mirim em um período de sete anos, ressalta-se que não se trata apenas de uma interação, mas de uma codependência das duas partes: a Santa Casa precisa atender ao SUS para garantir sua existência - no caso da Santa Casa de Mogi Mirim, o SUS representa mais de $80 \%$ de sua receita atual - enquanto a Prefeitura precisa que a Santa Casa atenda ao SUS por ser o único hospital com capacidade para atender ao convênio no município , já que não existem recursos disponíveis para a construção e operação de um hospital municipal.

\section{Referências}

BAHIA, L. Trinta anos de Sistema Único de Saúde (SUS): uma transição necessária, mas insuficiente. Cadernos de Saúde Pública, Rio de Janeiro, v. 34, n. 7, 2018 DOI: 10.1590/o102-311Xooo67218.

BAPTISTA, T. W. de F. História das políticas de saúde no Brasil: a trajetória do direito à saúde. In: MATTA, G. C.; PONTES, A. L. de M. (Org.) Políticas de Saúde: organização e operacionalização do Sistema Único de Saúde. Rio de Janeiro: EPSJV, 2007. p. 29.

BARRETO, M. R. N. A Santa Casa de Misericórdia da Bahia e a Assistência aos Doentes no Século XIX. In: SOUZA, C. M. C. de; BARRETO, M. R. N. (Org.). História da Saúde na Bahia: instituições e patrimônio arquitetônico (18o8-1958). Rio de Janeiro: Manole, 2011. p. 2-26.
CMB - CONFEDERAÇÃO DAS MISERICÓRDIAS

DO BRASIL. Santas Casas de Misericórdia e hospitais filantrópicos. In: CONFERÊNCIA NACIONAL DE SAÚDE. 9, 1992, Brasília, DF. Cadernos... Brasília, DF: UNB, 1992. p. 133-140.

CORDEIRO, H. As empresas médicas: as transformações capitalistas da prática médica. Rio de Janeiro: Graal, 1984.

GOYA, N. et al. Regionalização da saúde: (in)visibilidade e (i)materialidade da universalidade e integralidade em saúde no trânsito de institucionalidades. Saúde e Sociedade, São Paulo, v. 25, n. 4, p. 902-919, 2016. DOI: 10.1590/So104-12902016161198

MEDICI, A. C. Os serviços de assistência médica das empresas: evolução e tendências recentes. São Paulo: Iesp, 1992.

MIRANDA, G. M. D.; MENDES, A. da C. G; SILVA, A. L. A. da. O desafio da organização do Sistema Único de Saúde universal e resolutivo no pacto federativo brasileiro. Saúde e Sociedade, São Paulo, v. 26, n. 2, p. 329-335, 2017. DOI:

10.1590/So104-12902017168321

SANTOS, L. Sistema Único de Saúde: os desafios da gestão interfederativa. Campinas: Saberes, 2012.

VIANA, A. L. D.; MIRANDA, A. S. de; SILVA, H. P. da. Segmentos institucionais de gestão em saúde: descrição, tendências e cenários prospectivos. Rio de Janeiro: Fundação Oswaldo Cruz, 2015. Disponível em: <http://saudeamanha.fiocruz.br/ wp-content/uploads/2016/o7/2-PJSSaudeAmanha_ Textoooo2_final.pdf $>$. Acesso em: 1 fev. 2021.

\section{Contribuição dos autores}

Oliveira é responsável pela concepção e delineamento da pesquisa, redação do artigo e revisão crítica. Neto e Donadone são responsáveis pela aprovação da versão a ser publicada.

Recebido: 09/06/2021

Reapresentado: 25/02/2021; 09/06/2021

Aprovado: 27/09/2021

6 As intervenções de 2012 e 2019 e a tentativa de construir um hospital municipal foram demandadas pelo mesmo prefeito, mas em mandatos distintos (2009-2012 e 2017-2020). 